\title{
An evaluation of azathioprine in severe chronic asthma
}

\author{
N. G. HODGES ${ }^{1}$, R. A. L. BREWIS, and J. B. L. HOWELL \\ Manchester Royal Infirmary, Manchester
}

\begin{abstract}
Previous studies of immunosuppressive therapy in asthma have been uncontrolled and conflicting in their results. Two double-blind controlled cross-over trials using two dosage levels of azathioprine $(2 \mathrm{mg} / \mathrm{kg}$ and $5 \mathrm{mg} / \mathrm{kg}$ for three and four weeks respectively) in a total of 20 patients with chronic severe asthma are described. Both objective and subjective assessments by independent observers indicated no significant change in the groups as a whole. However, in four patients, an improvement was attributed to azathioprine therapy. Two patients in whom sputum production was copious showed marked clinical improvement and reduced sputum volume. In four patients, exacerbations of asthma occurred within two weeks of starting azathioprine and a causal relationship was suspected. No serious depression of circulating white blood cells occurred in any patient.
\end{abstract}

A minority of patients with asthma develop severe persistent symptoms which are poorly relieved by conventional therapy. Partial relief may be obtained with a high dosage of corticosteroids, but these carry a severe risk of side effects. The reasons for the poor response to treatment are obscure. The majority of these patients appear to have an 'intrinsic', non-allergic form of asthma (i.e., late onset, skin tests negative). However, the similarity of the clinical presentation to that in patients with proven allergic reactions and the presence of eosinophilia suggest that immunological mechanisms are involved.

Immunosuppressive therapy with various agents has been effective in certain diseases in which a disturbance of immunological mechanism has been suspected, e.g., rheumatoid arthritis (Mason et al., 1969), Crohn's disease (Brooke, Hoffmann, and Swarbrick, 1969), and chronic active hepatitis (Mackay, 1968). There are few reports of trials of immunosuppressive therapy in asthma and none of these has been adequately controlled. Waldbott (1952), using nitrogen mustard, reported unfavourable results in four cases. Cohen, Petty, Szentivanyi, and Priest (1965) obtained sustained improvement in a case of 'intrinsic' asthma using azathioprine over a period of five months. Kaiser and Beall (1966) obtained no improvement in three patients with chronic bronchial asthma treated with azathioprine in a dosage of $2 \mathrm{mg} / \mathrm{kg}$

1Correspondence to N.G.H., Southampton General Hospital, Southampton for four months. Arkins and Hirsch (1966) found no change in two patients with chronic perennial atopic asthma treated over a two-week period with 6-mercaptopurine. However, in two atopic dogs sensitive to ragweed pollen, Arkins, Gotway, Hogan, and Fink (1969) found that the asthmatic response to inhalation challenge was inhibited during a three-month period of treatment with 6-mercaptopurine. Fazio, Minetto, Sartoris, and Cavallero (1969) reported clinical improvement in 23 out of 25 cases of severe continuous asthma treated with methylhydrazine for between 10 and 30 days; improvement in respiratory function was noted in 16 cases. Nicolaescu, Drăgulescu, and Racoveanu (1969) treated seven cases of extrinsic asthma requiring high doses of corticosteroids with $100 \mathrm{mg}$ azathioprine for between three and six months; improvement occurred in two cases. Dubois dz Montreynaud et al. (1968) reported clinical improvement in 18 out of 21 cases of severe asthma of both intrinsic and extrinsic type when chlorambucil was given over periods of up to six months.

Following our own uncontrolled observation of beneficial effects of azathioprine in two patients with severe intractable symptoms we undertook a double-blind controlled trial of azathioprine in a larger group of such patients in whom the severity of the symptoms and the risk of serious corticosteroid side effects justified this approach. Azathioprine was selected because of reports that it may have a higher therapeutic index than other 
immunosuppressive agents (Nathan, Bieber, Elion, and Hitchings, 1961 ; Corley, Lessner, and Larsen, 1966; Bach, Dardenne, and Fournier, 1969). The results of this trial (trial 1) were encouraging but inconclusive, and we therefore repeated the trial in an enlarged group, using a higher dose schedule over a longer period of time (trial 2).

\section{METHODS}

Patients Patients with severe chronic asthma were selected from the Respiratory Clinic at the Manchester Royal Infirmary on the basis of at least one and usually both of the following criteria:

1. severe symptoms greatly interfering with life despite adequate conventional therapy;

2. a minimum tolerable daily dose of corticosteroids continuously greater than $10 \mathrm{mg}$ of prednisone (or equivalent) or side effects present on a lower dosage.

The experimental nature of the trial and the type and likelihood of possible side effects were explained to the patients who were then invited to participate.

All patients were in a stable state (i.e., not recovering from an acute illness) and were treated and assessed as out-patients. All other medication was kept constant unless the patient became more ill. Particulars of patients participating in trials 1 and 2 are detailed in Tables I and II respectively. Patients $b$ and $c$ of trial 1 and patient 10 of trial 2 were not taking corticosteroids at the time of the trial as this treatment had previously proved ineffective in these patients.

PROCEDURE In both studies, patients were allocated at random by a neutral observer to a sequence of either azathioprine followed by placebo or vice versa.

Trial 1 Each treatment period lasted for three weeks and the periods were separated by an interval of two weeks to minimize carry-over effect. Azathioprine was given in a dosage of $2 \mathrm{mg} / \mathrm{kg}$. The trial was

T A B L E I

TRIAL 1

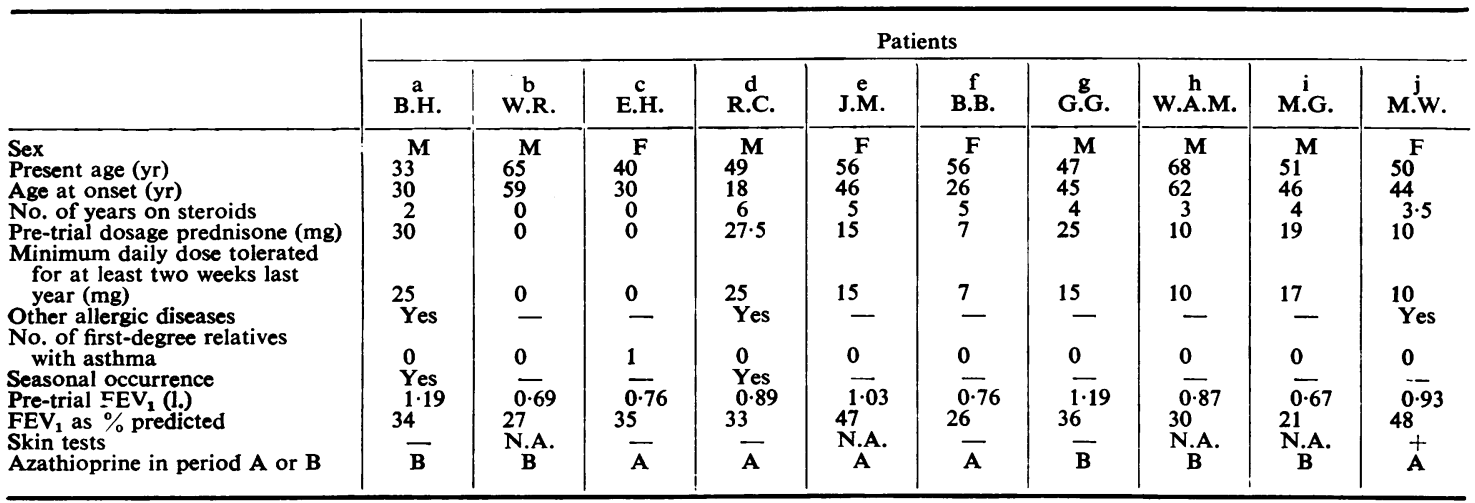

$\overline{-}=$ not present or negative; $+=$ positive to one or more antigens; N.A. $=$ not available.

\section{T A B L E I I}

TRIAL 2

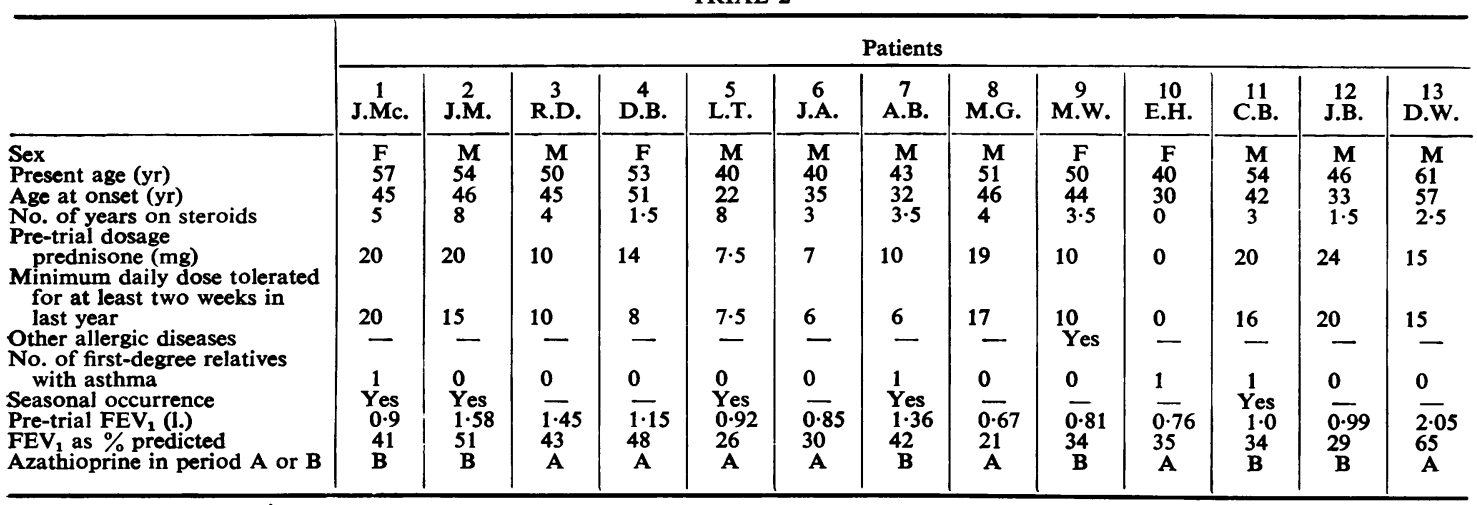

= not present or negative. 
double-blind and assessments (detailed below) which were made by three observers at the beginning and end of each period included clinical assessment, record card analysis, forced expiratory volume, blood gases, specific airway conductance, and daily sputum weights.

Trial 2 In trial 2, also a double-blind comparison with placebo, a higher dose of azathioprine was employed, $300 \mathrm{mg}$ or $5 \mathrm{mg} / \mathrm{kg}$ daily in two divided doses, whichever was the smaller. Each treatment was given for a period of four weeks, the second period following immediately on the first. Assessments (detailed below) were made independently by two observers at the start of the trial and at the end of each period; these included clinical assessment, record card analysis, grading of symptoms, forced expiratory volume and expiratory time. In addition, interim assessments were made.

ASSESSMENT The following assessments were made: Record cards Patients recorded their symptoms twice daily on a record card. The patients entered on the card a number between 1 (normal or no symptoms) and 10 (severe, virtually intolerable) for each of the following symptoms: wheeze, breathlessness, chest tightness, and cough. Sputum was graded from 0 to 5 for each 12-hour period: $3=$ no sputum, $1=a$ few specks only, 2 =approximately half an eggcupful, $3=$ one eggcupful, $4=$ two eggcupsful, and $5=$ greater than two eggcupsful. A note was made of the number of asthmatic attacks during the day, the number of times woken by breathlessness during the night, and any other treatment taken. All the patients were experienced in this technique as they were already using it to facilitate routine clinical assessments.

Clinical Assessment was based on history, physical examination, and a scrutiny of record cards (see above). Each observer made independent assessments without the knowledge of the results of objective tests. Each patient was judged at the beginning and end of each period to be better, unchanged or worse in comparison with the preceding period.

Grading of symptoms (trial 2 only) The patient recorded his assessment of wheeze and cough over the four-week period as a whole by making a mark on a 10-cm line labelled 'terrible' at one end and 'perfect' at the other, using one line for each symptom. The distance between the mark and the 'terrible' end of the line was measured (i.e., the lower the score the more severe the symptoms), recorded for each symptom and expressed as a percentage of the length of the line.

The patients also selected for themselves a position on a seven-point scale labelled with categories varying from 'much worse' to 'much better' for the following symptoms: difficulty climbing stairs, disturbance of sleep by dyspnoea at night, and chest tightness in the mornings.
Objective measurements The forced expiratory volume in one second (FEV 1 ) and forced vital capacity (FVC) were measured using a Vitalograph dry spirometer and the specific airways conductance (SGAW) was measured using a volume displacement plethysmograph (Mead, 1960). Measurements of $\mathrm{PCO}_{2}$ and $\mathrm{PO}_{2}$ were made on capillary blood from the warmed ear using Radiometer micro-electrodes and these were assumed to represent $\mathrm{PaCO}_{2}$ and $\mathrm{PaO}_{2}$ respectively. Throughout both periods of trial 1, patients made 24-hour collections of sputum which were weighed. Pulse rate, resting respiratory frequency, and forced expiratory time were also measured.

Interim assessments Patients were assessed twice weekly, most patients being visited in their homes. At each visit, patients were asked to select a position on a five-point scale to indicate the state of their chest symptoms. Peak expiratory flow using a Wright peakflow meter was measured and a sample of blood was taken for haematological examination (see below).

Side-effects and precautions At each assessment, patients were asked whether they had noted any adverse effects which they attributed to the trial treatment. The total white cell count was measured twice weekly. In trial 1 , an independent observer was responsible for scrutiny of the results of blood examinations. In trial 2, the results of half of the patients were known to one observer and the remainder to the other, in case the development of serious leucopenia made it necessary for one observer to break the code and modify the dosage. In the event, serious leucopenia did not occur in either trial and all observers remained 'blind' until after calculation of the results.

In trial 2 , an attempt was made to quantify symptoms to a greater degree and fewer objective tests were made.

\section{RESULTS}

TRIAL 1 Of the 10 patients taking part two were withdrawn; one developed dyspepsia and nausea on azathioprine and the other developed increased breathlessness requiring other treatment. Eight patients completed the study.

Clinical assessment The results of the observers' independent assessments are shown in Table III. Improvement on azathioprine in most cases was regarded as slight, but in patients a and $d$ it was marked and quite exceptional compared with the response to all previous treatment.

Record card analysis Seven of the eight patients completing trial 1 filled in the record cards adequately. Each symptom was considered separately and the mean daily symptom score for 
the group as a whole was calculated for the last week in each period. In no case was a significant difference between the treatment and placebo periods noted.

T A B L E II I

TRIAL 1; CLINICAL ASSESSMENT FOR AZATHIOPRINE PERIOD COMPARED TO PLACEBO

\begin{tabular}{|c|c|c|c|}
\hline Patient & Observer 1 & Observer 2 & Observer 3 \\
\hline $\begin{array}{l}\mathbf{a} \\
\mathbf{c} \\
\mathbf{d} \\
\mathrm{e} \\
\mathbf{f} \\
\mathrm{h} \\
\mathbf{i} \\
\mathbf{j}\end{array}$ & $\begin{array}{l}\text { Better } \\
\text { Unchanged } \\
\text { Better } \\
\text { Worse } \\
\text { Better } \\
\text { Unchanged } \\
\text { Unchanged } \\
\text { Better }\end{array}$ & $\begin{array}{l}\text { Better } \\
\text { Unchanged } \\
\text { Better } \\
\text { Better } \\
\text { Better } \\
\text { Worse } \\
\text { Worse } \\
\text { Better }\end{array}$ & $\begin{array}{l}\text { Not seen } \\
\text { Unchanged } \\
\text { Not seen } \\
\text { Unchanged } \\
\text { Better } \\
\text { Better } \\
\text { Worse } \\
\text { Better }\end{array}$ \\
\hline
\end{tabular}

Objective criteria Azathioprine induced no significant improvement in spirometric tests, $\mathrm{PaO}_{2}$ or $\mathrm{PaCO}_{2}$ (Table IV). There was a small improvement in airway conductance in the azathioprine period compared with both control and placebo periods which reached significance at the $5 \%$ level in the latter comparison. The mean daily weight of the sputum (Table V) showed a fall in two patients ( $a$ and $d)$, but there was little change in the remainder. One patient had scanty sputum continuously and one did not collect it satisfactorily.

\section{T A B LE I V}

TRIAL 1: CHANGE IN OBJECTIVE MEASUREMENTS

\begin{tabular}{|c|c|c|c|c|}
\hline \multirow{2}{*}{ Measurement } & \multicolumn{2}{|c|}{$\begin{array}{l}\text { Advantage Azathio- } \\
\text { prine over Control }\end{array}$} & \multicolumn{2}{|c|}{$\begin{array}{c}\text { Advantage Azathio- } \\
\text { prine over Placebo }\end{array}$} \\
\hline & $\begin{array}{c}\text { Mean Change } \\
\text { in Value }\end{array}$ & $\mathbf{P}$ & $\begin{array}{c}\text { Mean Change } \\
\text { in Value }\end{array}$ & $\mathbf{P}$ \\
\hline $\begin{array}{l}\mathrm{PaO}_{2}(\mathrm{mmHg}) \\
\text { FEV }_{1}(1 .) \\
\text { FVC (1.) } \\
\text { SGaw (1./sec/mmHg) }\end{array}$ & $\begin{array}{l}-6 \\
+0 \cdot 13 \\
-0.28 \\
+0.01\end{array}$ & $\begin{array}{l}<\overline{0.1} \\
<\overline{0.1}\end{array}$ & $\begin{array}{l}+1.5 \\
+0.12 \\
+0.39 \\
+0.01\end{array}$ & $\begin{array}{l}<0.1 \\
<0.1 \\
<0.1 \\
<0.05\end{array}$ \\
\hline
\end{tabular}

T A B LE V

TRIAL 1: SPUTUM WEIGHTS

\begin{tabular}{|c|c|c|c|c|c|}
\hline \multirow{3}{*}{\multicolumn{2}{|c|}{ Patient $^{1}$}} & \multicolumn{4}{|c|}{ Mean Daily Sputum Weight (g) } \\
\hline & & \multicolumn{2}{|c|}{ Total 3-week Period } & \multicolumn{2}{|c|}{ Last Week of Each Period } \\
\hline & & Placebo & Azathioprine & Placebo & Azathioprine \\
\hline $\begin{array}{l}\mathbf{a} \\
\mathbf{d} \\
\mathbf{e} \\
\mathbf{f}\end{array}$ & $\begin{array}{l}\text { B.H. } \\
\text { R.C. } \\
\text { J.M. } \\
\text { B.B. } \\
\text { W.M. } \\
\text { M.W. }\end{array}$ & $\begin{array}{r}83 \\
105 \\
16 \\
26 \\
21 \\
31\end{array}$ & $\begin{array}{l}63 \\
34 \\
22 \\
33 \\
24 \\
34\end{array}$ & $\begin{array}{l}84 \\
93 \\
16 \\
22 \\
21 \\
26\end{array}$ & $\begin{array}{l}69 \\
35 \\
17 \\
30 \\
25 \\
41\end{array}$ \\
\hline
\end{tabular}

'Two other patients completed the trial; one had scanty sputum continuously and one did not collect it satisfactorily.
White cell counts There was no significant change in the white cell count in either period.

TRIAL 2 Thirteen patients began trial 2. Four patients were withdrawn during the first period. Patient 1 was on placebo and developed an ulcerative pharyngolaryngitis ; three patients $(8,10$, and 13) developed an exacerbation of asthma approximately one week after starting azathioprine. The deterioration did not appear to be due to bronchial infection. Results are presented for the nine patients who completed the trial.

Clinical assessment (Table VI) The number of patients assessed as being better, the same or worse was similar in each period, but in both periods the majority were better than in the initial assessment.

\section{T A B LE VI}

TRIAL 2: CLINICAL ASSESSMENT BY INTERVIEW AND EXAMINATION OF NINE PATIENTS (TWO OBSERVERS, i.e.,
TWO ASSESSMENTS PER PATIENT)

\begin{tabular}{l|c|c|c|c}
\hline \multicolumn{1}{c|}{ Assessment } & Better & Same & Worse & $\begin{array}{c}\text { Total No. of } \\
\text { Assessments }\end{array}$ \\
\cline { 1 - 2 } $\begin{array}{l}\text { Initial (prior to } \\
\text { period A) }\end{array}$ & 6 & 6 & 6 & 18 \\
$\begin{array}{l}\text { Following } \\
\text { azathioprine } \\
\text { Following placebo }\end{array}$ & 11 & 3 & 3 & $17^{1}$ \\
\end{tabular}

'Two observer/patient interviews did not occur at the correct time.

Record card analysis No significant difference was found between the two periods with respect to any symptom. As it seemed possible that, in those patients receiving azathioprine in the first period, the effects might be carried over into the second period, the mean weekly total symptom scores were analysed for each patient. Patients 3, 4 , and 5 showed a fall in symptom score which persisted into the placebo period, when the lowest scores were seen. Although the lowest scores in these patients were seen after azathioprine had been withdrawn, there were already well-marked falls in symptom scores in the third and fourth weeks of treatment. Because a similar fall in symptom score was not seen in any patient receiving azathioprine second, these results suggest that the symptom scores on patients 3,4 , and 5 either improved by chance or that these patients responded differently from others.

Graded symptoms and objective measurements Assessments of wheeze and cough (lines 1 and 2), climbing stairs, morning tightness, night disturbance, and spirometric data demonstrated no significant $(P<0.5)$ improvement in the azathioprine 
as compared with the placebo period. In some instances there was a significant improvement but this was matched by an equal improvement in the placebo period. Interim assessments, including peak flow rate, also showed no significant difference between the two periods. The mean peak flow rate in the azathioprine period was $2101 / \mathrm{min}$ (S.D.68) and that in the placebo period $2201 / \mathrm{min}$ (S.D.96).

Side effects Two of the patients who completed the trial complained of mild dyspepsia while taking azathioprine. One patient developed severe herpes labialis during the azathioprine period. No other side effects were noted.

The mean white blood cell count during the placebo period was $10,377 / \mathrm{mm}^{3}$ (S.D. 3,000 ) and that during the azathioprine period $8,922 / \mathrm{mm}^{3}$ (S.D. 2,930). The differences are statistically significant $(P<0.02)$.

\section{DISCUSSION}

TRIAL 1 The dosage of azathioprine was not associated with any significant change in the white cell count of the eight patients on this treatment. The observers' assessment that there was little, if any, improvement in most cases was in agreement with the results of record card analysis and most of the objective tests, though airways conductance was significantly higher in the azathioprine period. Two patients, however, were distinctly improved during the azathioprine period and their subsequent course deserves comment.

Patient a A university lecturer aged 33 years had been troubled persistently for two years with shortness of breath, wheezing, irritating cough, and waking with breathlessness, usually four times a night. He produced large quantities of viscid sputum, usually non-purulent. Prednisone dosage was rarely less than $20 \mathrm{mg}$ a day during this period. A particular complaint was that he was unable to lecture comfortably. Two weeks after starting azathioprine he noted improvement in his symptoms, particularly in his ability to speak long sentences without breathlessness. The irritating cough and sputum volume also lessened and the breathless attacks at night were reduced to less than once a night. Improvement continued until two weeks after the end of the azathioprine period, when his symptoms returned and progressed over the next week to the same stage as before the trial. The most striking objective change was in the sputum weight (Table IV), though the FEV improved from $1 \cdot 191$. to $2 \cdot 221$. and the SGAW from $0.0251 . / \mathrm{sec} / \mathrm{cm} \mathrm{H}_{2} \mathrm{O}$ to $0.0571 . / \mathrm{sec} / \mathrm{cm} \mathrm{H}_{2} \mathrm{O}$. After this trial he pressed for a resumption of azathioprine ; improvement again occurred, varying directly with the dose of azathioprine of between 2 and $5 \mathrm{mg} / \mathrm{kg}$, and this persisted throughout the six-month period of follow-up. Life was much more comfortable and he was able to resume lecturing. He still required corticosteroids, though in a much reduced dosage of $12 \cdot 5 \mathrm{mg}$ daily.

Patient $d$ This patient, aged 49 years, was similar, his main complaints being wheezing, effort dyspnoea, and nocturnal dyspnoea, but sputum production was even greater than in patient $a$. He had required more than $20 \mathrm{mg}$ of prednisone a day for two years, on which dose his symptoms were still severe. One week after starting azathioprine he noted improvement, which continued until the end of the trial and persisted for two weeks after stopping azathioprine. The most striking objective finding was a reduction of sputum weight on azathioprine and the $\mathrm{PaO}_{2}$ rose from $63 \mathrm{~mm}$ on placebo to $82 \mathrm{~mm}$ on azathioprine. Improvement was so marked and deterioration on stopping azathioprine so clear that azathioprine was restarted, again with marked improvement. Over the next six months the dosage was increased and the prednisone dosage reduced. The total white cell count was reduced to 4,000 / $\mathrm{mm}^{3}$ on a temporary dosage of $8 \mathrm{mg} / \mathrm{kg}$ azathioprine. His symptoms were less troublesome than before and the prednisone was reduced to $10 \mathrm{mg}$ a day.

TRIAL 2 Even with the higher dosage of this trial, we were convinced of worthwhile improvement in only two cases (patients 4 and 5) and these were not as striking as cases a and $d$ of trial 1. Symptoms improved within two weeks of starting azathioprine in the first period, and this was maintained until the end of the second period, when deterioration again occurred. All other assessments in patient 4 and most of the assessments in patient 5 also improved in the azathioprine period as opposed to the placebo period. Patient 2 was notable in that both observers regarded him as clinically improved on azathioprine and the assessments of graded symptoms and objective data also suggested improvement but the record card scores showed little difference.

Apart from these individual cases, all the assessments taken together show no change in the azathioprine as compared with the placebo period. 
The improvement noted in the two patients in trial 2 could have occurred by chance, but we think this unlikely because these patients were previously persistently ill. It is also unlikely that cases $a$ and $d$ in trial 1 improved by chance because of the clear relation between the severity of their symptoms and starting and stopping azathioprine.

Of the whole group, the two patients who benefited most were in fact those with the largest sputum production. An uncontrolled observation in another patient with copious sputum suggested that azathioprine was effective in reducing the sputum volume.

The exacerbations of asthma in patients 8,10 , and 13 of trial 2 and in patient $g$ of trial 1 , all of whom were withdrawn from the study, are of interest. Two had been comparatively stable for at least six months and two for several years. The episode of worsening began with malaise and a marked increase in wheezing and breathlessness in each case. There was no change in the cough and sputum and no evidence of bronchial infection. Their treatment was changed in that steroids were increased and antibiotics given. Hence they were withdrawn from the trial. The patients' white cell counts were normal at this time. These exacerbations occurred within one week of starting azathioprine and suggested that azathioprine was responsible, especially as only one exacerbation of asthma occurred in the placebo period and that in a patient subject to more frequent exacerbations than these patients.

The patients in this study were selected on purely clinical grounds and variability of individual responses to immunosuppression may be due to the presence of different aetiological mechanisms.

\section{CONCLUSION}

Although we have been unable to demonstrate any significant effect of azathioprine in this group of patients with severe chronic asthma as a whole, the response of some individuals within the group, particularly the two with markedly increased sputum production, suggests that the drug may have a beneficial effect in a minority of such patients. Where symptoms are particularly trouble- some and intractable, we believe a careful therapeutic trial of azathioprine is justified. However, there is the possibility that in some patients exacerbation may be precipitated and long-term toxic effects may occur. Further studies are clearly required to determine the place of immunosuppressive therapy in asthma.

\section{REFERENCES}

Arkins, J. A., Gotway, C. A., Hogan, M. R., and Fink, J. N. (1969). The effect of 6-mercaptopurine on spontaneous canine asthma. J. Allergy, 44, 108.

- and Hirsch, S. R. (1966). Clinical effectiveness of 6mercaptopurine in bronchial asthma. J. Allergy, 37, 90.

Bach, J. F., Dardenne, M., and Fournier, C. (1969). In vitro evaluation of immunosuppressive drugs. Nature (Lond.), 222, 998.

Brooke, B. N., Hoffmann, N. D. C., and Swarbrick, E. T. (1969). Azathioprine for Crohn's disease. Lancet, 2, 612.

Cohen, E. P., Petty, T. L., Szentivanyi, A., and Priest, R. E. (1965). Clinical and pathological observations in fatal bronchial asthma. Ann. intern. med., 62, 103.

Corley, C. C. Jr., Lessner, H. E., and Larsen, W. E. (1966). Azathioprine therapy of "autoimmune" diseases. Amer. J. Med., 41, 404.

Dubois de Montreynaud, J. M., Doco, Kochman, S., Charreire, J., and Fondeville, D. (1968). Interêt dans le traitement de certains asthmes d'une médication à effet immunodépresseur, le chlorambucil, expérience personnelle. Ann. méd. pharm. Reims, 5, 293.

Fazio, M., Minetto, E., Sartoris, S., and Cavallero, P. (1969). Le traitement de l'asthme bronchique chronique par la méthylhydrazine. Presse méd., 77, 1996.

Kaiser, H. B., and Beall, G. N. (1966). Azathioprine (Imuran) in chronic asthma. Ann. Allergy, 24, 369.

Mackay, I. R. (1968). Chronic hepatitis: effect of prolonged suppressive treatment and comparison of azathioprine with prednisolone. Quart. J. Med., 37, 379.

Mason, M., Currey, H. L. F., Barnes, C. G., Dunne, J. F., Hazleman, B. L., and Strickland, I. D. (1969). Azathioprine in rheumatoid arthritis. Brit. med. J., 1, 420.

Mead, J. (1960). Volume displacement body plethysmograph for respiratory measurements in human subjects. J. appl. Physiol., 15, 736.

Nathan, H. C., Bieber, S., Elion, G. B., and Hitchings, G. H. (1961). Detection of agents which interfere with the immune response. Proc. Soc. exp. Biol. (N.Y.), 107, 796.

Nicolaescu, V., Drăgulescu, I., and Racoveanu, C. (1969). Consideratii asupra tratamentului imunosupresiv in astmul bronsic. Stud. Cercet. Med. intern., 10, 257.

Waldbott, G. L. (1952). Nitrogen mustard in the treatment of bronchial asthma. Ann. Allergy, 10, 428. 